Article

\title{
Are the Most Effective Approaches towards Helping Students with Emotional Behavioural Disorders (EBDs) Predisposed and Trait Based?
}

\author{
Melinda J. Metaxas
}

check for updates

Citation: Metaxas, M.J. Are the Most Effective Approaches towards Helping Students with Emotional Behavioural Disorders (EBDs) Predisposed and Trait Based?. Psychiatry Int. 2021, 2, 85-107. https://doi.org/10.3390/ psychiatryint 2010007

Received: 31 January 2021

Accepted: 18 March 2021

Published: 21 March 2021

Publisher's Note: MDPI stays neutral with regard to jurisdictional claims in published maps and institutional affiliations.

Copyright: (C) 2021 by the author. Licensee MDPI, Basel, Switzerland. This article is an open access article distributed under the terms and conditions of the Creative Commons Attribution (CC BY) license (https:// creativecommons.org/licenses/by/ $4.0 /)$.
Melinda Metaxas \& Associates Pty Ltd., Bendigo, VIC 3550, Australia; assessments@melindametaxas.com

\begin{abstract}
Trait emotional intelligence (EI) may prove to be most valuable as an approach for dealing with others' behaviours/emotions via its related psychological processes. Personality trait theory posits that an individual's level of EI affects their cognitive-affective-behavioural reaction towards students with emotional behavioural disorders (EBDs) and influences the level of difficult behaviour. EI would be an essential element in fostering supportive interactions with students as a way of preventing and/or managing disruptive behaviours. The author explores which individuals are more predisposed to discriminate against EBD students using an attribution model framework and identifies the most effective and supportive EI traits. Two hundred and sixty-one teachers from 51 Victorian schools completed self-report questionnaires, including the Trait Emotional Intelligence Questionnaire. A quantitative survey methodology used vignettes (depicting a student with either mild or severe EBD symptoms), with 50/50 surveys randomly distributed. Teacher EI predicted the behaviour towards students with EBDs, whilst bypassing or biasing conscious thought processing. Combinations of EI traits were identified that produced the most desirable outcomes, demonstrating EI's propensity to direct reactions towards a more effective or dysfunctional helping approach. The findings suggest that the most effective approaches towards helping EBD students are the innate dispositional reactions that establish the necessary psychological foundations for any successful interaction or outcome. The development of an assessment tool (Assessment Screen for Emotionally Intelligent Teachers (ASET)) lays a sound foundation for profiling teachers with these ideal qualities.
\end{abstract}

Keywords: emotional intelligence; trait; emotional behavioural disorders; attribution theory; teachers; special education; discrimination

\section{Introduction}

Efforts continue in the research field to find effective strategies to manage and support students with emotional behaviour disorders (EBDs); however, variation has been found in the use and effectiveness of such approaches [1-6]. What if the best practice lies within the facilitator rather than with the strategy? The current article argues that this inconsistency is a result of individual characteristics such as trait emotional intelligence, varying reactions towards the challenging behaviour and the way professionals interrelate with students with EBDs. Behaviour management strategies require more than just an instructional step-by-step, assumedly emotionally detached, practical application.

It is important for any professional working with emotional behavioural disorder (EBD) children to understand how the quality of their emotional approach towards such challenging and vulnerable student presentations greatly influences the student $[7,8]$. It is important to understand the factors and processes that influence high-quality interactions, such as the ability to cope and regulate emotions to promote supportive relationships as a way of preventing and managing disruptive behaviour $[9,10]$. It is also important to identify the characteristics that could be deemed disadvantageous as well as identify some of the positive and negative effects of such emotional intelligence (EI) traits on helping EBD students. 
Students with emotional behavioural disorders are perceived to be the most challenging and difficult group of students to manage [11]. There is no agreed-upon definition across Australian states and territories to represent children with emotional or behavioural problems. Cumming [12] identified terms currently used in Australia, such as mental health disorder, mental health concerns, disruptive behaviour disorder, conduct disorder and socially unacceptable behaviours. The emotional and behavioural problems occur over a long period of time and to a marked degree [13]. Students can fall within psychological diagnostic categories found within the Diagnostic and Statistical Manual of Mental Disorders-Fifth Edition (DSM-V) [14], such as mood disorders, oppositional defiant disorder, attention-deficit hyperactivity disorder, conduct disorder, psychotic disorders, eating disorders and anxiety disorders $[15,16]$. In the Australian context, mental health disorders, behaviour disorders and disabilities tend to co-exist. Students with EBDs have continued to be of increasing concern for teachers in Australian classrooms for decades [17].

As students with EBDs are commonly educated in Australian mainstream classrooms, this highlights the important role that general and special education teachers have to play for such students. The level of emotional support from teachers not only affects their interactions with students but also plays a significant role in students' adjustment, development, emotional well-being and academic achievement [9]. Most interventions for students with EBDs have tended to focus on the students' development, and 'there has been little focus on teachers' own development despite evidence that teachers make important contributions to desirable classroom and student outcomes' [9] (p. 496), [18].

Teacher approaches can impact significantly on whether student behaviours are maintained or intensified $[19,20]$. Punitive and exclusionary reactions have been found to increase and escalate challenging behaviour [21-23]. Many links are already established between teachers' emotional experiences and emotional competencies and the manner in which they engage, instruct and manage students' misbehaviour [3,24-26]. Students gain information about their performances from teacher cues [27], which contributes to how they perceive themselves, influencing their self-esteem and own emotional response and behaviours. An increase in a teacher's negative perceptions and behaviours towards a student with an EBD negatively acts as a cyclical process, which escalates student behaviour $[10,28]$. The severity of EBD symptoms has been shown to reduce when teachers possess particular skills, even those disorders with biological components, such as attention-deficit hyperactivity disorder (ADHD) [29]. Students with EBDs receive varying amounts of help and support from their teachers as a result of how teachers perceive them $[5,30]$-hence the importance of exploring teacher characteristics such as EI and reactional approaches in helping students with EBDs.

Helping behaviours refer to a teacher's willingness to become proactively and supportively involved with an EBD student, despite their difficult presentation. This refers to teacher behaviours that are more likely to bring about positive and/or longer-term change for the student [31]. This can be measured through the willingness of a teacher to use strategies that help promote positive teacher-student interactions. On the other hand, punitive behaviours, also referred to as discriminatory behaviours in this study, are intended to bring about the immediate cessation of difficult behaviour through the use of authority or quick fixes. Such methods do not assist the student with longer-term change. Punitive strategies can include avoiding the student, transferring the student to another class, making threats, preaching, punishing and withholding privileges [31]. Such punitive behaviours often create distance between teachers and students, limiting the communication and interaction between them and does not contribute to the effective integration of the challenging student into the environment. A teacher's lack of willingness to support or help a student may be an example of a discriminatory consequence for the student as a result of their teacher's perception.

Stigmatisation precedes discriminatory behaviour and refers to the cognitive perceptions that teachers have regarding a student with an EBD presentation. Stigma exists when people experience 'discrimination that leads to unequal outcomes' [32] (p. 365), such as 
withholding opportunities, being emotionally or behaviourally rejective or reacting punitively. Stigma is a process that commences with a stigmatising trigger (such as challenging behaviour) and progresses through a cognitive-affective process to result in discrimination [33]. It must be highlighted that this behavioural process is not necessarily suggesting intent or insight. There is far more known about the conscious or cognitive processes of stigmatisation towards individuals than the unconscious or intrinsic characteristics that are difficult to observe or measure. This study presents one way to capture and measure these invisible contributors.

Personality trait theory has rarely been seen within such studies of stigmatisation. There is generally a focus of the stigmatised individual as possessing particular personality traits or characteristics, for example, rather than the stigmatiser's personality being the source of the stigmatisation. To date, it appears that no studies have explored an individual's cognitive-emotional-behavioural reaction as related to their trait EI. Many studies suggest that further insight into teacher reactions towards difficult behaviour can be gained through the attributional process [34,35]. The popular cognitive attribution model of stigmatisation has not been considered as a consequence of trait EI within personality trait theory, let alone within the context of behavioural disorders. The introduction of a measure of trait EI adds a further dimension and school of thought to the cognitive theory of attribution.

This study demonstrates the applicability of a new attribution model developed by the researcher, namely the EI Process Model of Stigmatisation (EPS-Model). The EPS-Model is based on the theoretical and statistical arrangement of existing models and variables that can capture and measure the most effective inherent approaches towards EBD students. The model also assisted with the development of an assessment tool (Assessment Screen for Emotionally Intelligent Teachers (ASET)) that enables profiling of the highly desired qualities or EI traits required to effectively help students with EBDs or special needs. The tool psychometrically identifies those who possess the most essential traits that lead to the most effective and supportive approaches.

\subsection{Attribution Theory}

Corrigan et al. [36] developed an attribution pathway model that they applied to mental illness stigma. Their model denotes the directional relationship between events, attributions, affect and behavioural reactions. Corrigan et al.'s model was adapted from Weiner's original work [37-39]. Generally, research suggests that attributions of perceived uncontrollable events tend to lead to pity and helping behaviour. An assumption of Weiner's model is that the cognitive-affective-behavioural concept can be applied to any helping behaviour, especially classroom-related thoughts and actions [40-42]. He believed that it is essential to understand teachers' perceptions in order to explain their helping behaviour, as well as their affective reactions as a consequence of their causal attributions.

Corrigan et al. [43] found, through the attribution process, that students with intellectual disabilities were more stigmatised in terms of the stability of their condition (e.g., permanence of their disability), compared with mental illness that was associated with a higher degree of controllability (i.e., responsible for their disabilities). The concept of examining others and making causal judgements about the reasons for their presentation is not a new concept [26]. If the cause of a situation is attributed to factors within the individual's control [44] (p. 950), the person is likely to be negatively judged as responsible for the cause of their condition or behaviour. Alternatively, if the situation is attributed to factors outside of the individual's control, such as biology, genetics or head injury, they are viewed more favourably and less responsible $[44,45]$. When this pattern is applied to students with EBDs, it is assumed that the less control that teachers believe the students have over their presentation, the more likely they are to offer help compared with teachers who perceive the students to be in control. Teachers tend to attribute child or family factors to students with behavioural difficulties, while few studies recognise the importance of teaching factors as primary external contributors to the problematic behaviour. The rela- 
tionship between causal attributions, mediating affect and consequent behaviour has been validated in several studies [46-49], including helping behaviour [40,50,51] and challenging student behaviour [34,35,52].

The observed nature of a child's presentation and the extent of the problematic behaviours leads to stigmatising judgements and resultant discriminatory behaviours [51]. Social psychology theories or perspectives regarding stigmatisation tend to focus on a person's presentation or behaviour as being a primary source of stigmatisation that attributes blame. The current study aims to shift the focus and blame away from EBD students by considering other factors, such as teachers' innate EI traits, as the central influence behind stigmatisation and discrimination. The relationships between student behaviour severity, EI trait factors, cognitive perceptions of self and environment, and emotional reactions are examined as a starting point in understanding stigmatisation, or the variables that may relate to supportive helping outcomes for EBD students.

\subsection{Social Cognitive and Decision-Making Theories and Behaviour}

Poulou and Norwich [3] proposed a similar model to Corrigan et al.'s [36] that aimed to construct a portrayal of teachers' cognitive, emotional and behavioural responses, specifically towards students with EBDs. As in the current study, Poulou and Norwich [3] asserted that teachers have the greatest influence on student outcomes; therefore, they explored additional psychological processes behind teachers' reactions and decision making. Teachers' cognitive perceptions of the remedial nature of presentations of students with EBDs, their ability to bring about positive outcomes for students (self-efficacy) and their perception of how much control (personal responsibility) they have over the student presentation predicted their intended helping behaviour [3]. In a more recent study, the challenging behaviour of students led teachers to attribute causes that made them decide the student was beyond help [1]. Therefore, a teacher's sense of their own level of control over a student's presentation may be an important factor in whether, or how, interventions are implemented.

Self-efficacy is another well-established predictor of teacher reaction and helping behaviour. Such perceptions of self-efficacy relate to teachers' beliefs about their own confidence and skills in managing, coping, teaching and engaging with an EBD student. It has also been found to relate to teachers' EI [53-56]. Teacher self-efficacy positively correlated with helpful response styles in regard to real incidents and hypothetical incidents of social rejection, shyness, low achievement and passive-aggressive behaviour. Self-efficacy also related to teachers' reports on using appropriate teaching strategies [57], managing classroom social problems [58] and implementing positive classroom management strategies [59]. Self-efficacy has also been a dominant factor related to perceived ability in handling difficult behaviours [59-61]. Self-efficacy is generally considered a significant predictor of teacher reactions and helping behaviour, so it was important to include this variable in the current study.

The literature records at least two established factors that interfere with a person's decision to help, which are considered to be exceptions to predictable patterns of helping behaviour. That is, individuals tend to habituate to a behaviour when they are regularly and frequently exposed to that behaviour [62] and when there is a perceived risk associated with helping another person. Perceived risk has been found to significantly predict helping behaviour in studies on stigmatisation $[37,63]$. Many mental illness studies have found relationships between perceiving someone as dangerous and fearing them [64-67], which leads to avoidant behaviours. Weiner [37] believes that an emotional response like fear produces a behavioural outcome, such as avoidance, without necessarily requiring a mediating attribution.

\subsection{Theories of Emotion, Emotional Intelligence and Behaviour}

There is no general agreement on the functions or relationship of cognition and affect leading to behavioural outcomes. Lazarus [68] argued that emotions must have some 
cognitive purpose and that the interpretation of an emotional context may be conscious or subconscious. Other theories, however, claim that emotion is separate from and can precede cognition. Mood-congruency models propose that affect tends to bias the content of thoughts towards the emotional state being experienced [69]. Affect tends to direct thought content towards the way one is feeling [70].

To illustrate discrepancies found between cognition and behaviour, Almog and Shechtman [60] revealed that teachers have sufficient knowledge regarding helpful strategies but that they are unable to apply this knowledge practically in real situations. Contrary to many other self-report studies [71,72] that while teachers prefer the use of helpful approaches, in reality, teachers adopt restrictive responses more often than helpful ones. This suggests that there must be a stronger drive or predictor than just cognitive intention towards a particular approach, such as EI and emotion.

The bulk of emotion-related research seems to involve theories regarding emotional regulation [73-76], which is relevant to whole classroom behaviour management, defusing emotionally charged situations $[77,78]$ and student behavioural outcomes [9]. Teachers difficulty with emotional regulation has been found to affect teacher-student relationships [10] and handling of persistent emotionally provocative situations [77]. A decrease in patience and a flattening of affect can additionally occur with expressions of negativity towards students. The more stress teachers experience, the less tolerant they become of difficult behaviours [2]. The teachers' inability to regulate their own emotions, feel empathetic and emotionally express themselves, for example, may have serious implications for student behaviour.

A clear distinction is made in this study between emotional dispositions (EI character traits) that are possessed by a person that then predisposes them to experience certain emotional states. Petrides' trait EI claims to include all 'personality facets that are specifically related to affect' [79] (p. 274). Substantial disagreements regarding the terminology and operationalisation of EI have led theorists to start clustering EI into different theoretical models of EI. There are currently three main groups of contemporary EI models [80], namely ability, trait and mixed EI models, where main differences in these models rest in the way they are measured [81]. Mayer, Salovey and Caruso developed an EI mental ability or information processing approach that relates more to cognitive ability tests than personality [82]. Bar-On's [83-85] mixed model is personal skills based, not primarily trait based. Goleman [86] made a distinction between emotional competencies and EI, suggesting that competencies are defined as learned skills or capabilities that increase work performance, whereas EI is the basis upon which these skills are learnt. The current study supports Goleman's differentiation between the two terms. Petrides [87] (p. 137) defines trait EI as 'a constellation of emotional self-perceptions located at the lower levels of personality hierarchies and measured via the trait emotional intelligence questionnaire'. Petrides' [88] theoretical model of trait EI forms the theoretical framework of the current study.

\subsection{Conceptual Framework}

Trait EI is founded on assumptions that underpin personality trait theory that views personality as a set of traits possessed by a person that uniquely influences his or her cognitions, emotions and behaviours in various situations. The DSM-IV defines personality traits as 'enduring patterns of perceiving, relating to, and thinking about the environment and oneself that are exhibited in a wide range of social and personal contexts'. It is fair to assume from such personality theories that a teacher's trait EI would influence the whole attribution process, that is, teachers' cognitive-affective-behavioural reactions to EBD students.

By drawing on attribution theory as the general methodological framework [36,89], this study explores teachers' causal attributions and cognitive-emotional-behavioural processes that lead them to either help or punish students with severe emotional and behavioural disorders. This study is also influenced by Poulou and Norwich's [3] process model, which outlines other important factors that relate to helping behaviour. It also 
importantly explores the influence of teachers' trait EI on these factors and process. The study tests new as well as existing factors found in the literature that help explain the link between nominated teacher factors and student misbehaviour. The attribution process model measures discrimination levels through its established application to various helping behaviours [36,90-92]. The hypothesised model (Figure 1) is presented below.

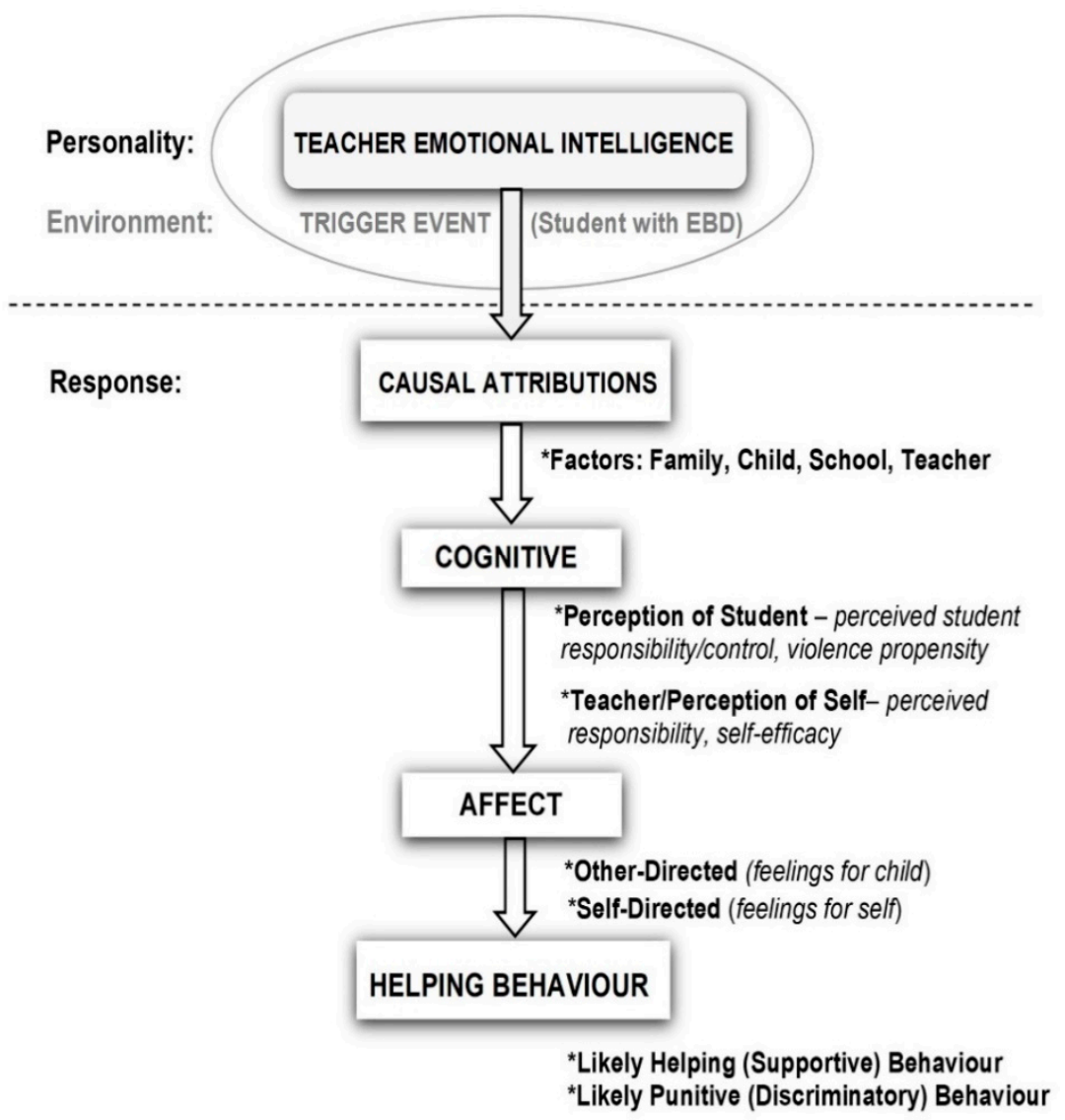

Figure 1. Hypothesised model of teachers' emotional intelligence (EI) that leads them to either help or punish students with severe emotional and behavioural disorders.

\subsection{Objectives and Hypotheses}

\subsubsection{Objective 1: Attribution Model Variables}

The aim of this study was to examine emotional intelligence (EI) traits and other characteristics that predict supportive rather than punitive behavioural approaches towards students with emotional behavioural disorders. This objective related to the general research question, Are some teachers predisposed to discriminate against students with emotional behavioural disorders? How are students with EBDs perceived and treated based on the level of EI, and does level of EI increase or decrease stigmatisation and the resultant discriminatory behaviour? The main hypothesis is that teachers who have higher EI will be less stigmatising and punitive and the likelihood of helping behaviours by those teachers will be higher. In addition, there will be a relationship between teachers' EI traits and their (cognitive, affective and behavioural) responses towards students with EBDs. These hypotheses are displayed in Table 1. 
Table 1. Predicted teacher outcomes of the trait EI Process Model of Stigmatisation.

\begin{tabular}{cccc}
\hline Teacher EI & Cognitive & Affective \\
\hline High EI & $\rightarrow$ & Lower Student Control & Behavioural \\
& & $\begin{array}{c}\text { Higher Personal Response } \\
\text { Higher Self-Efficacy } \\
\text { Lower Perceived Risk }\end{array}$ & $\begin{array}{c}\text { Higher Compassion } \\
\text { (Other-Directed) } \\
\text { Lower Negative Affect } \\
\text { (Self-Directed) }\end{array}$ \\
\hline Low EI & $\rightarrow$ & Higher Student Control & Lower Compassion \\
& & Lower Personal Response & (Other-Directed) \\
& & Lower Self-Efficacy & Higher Negative Affect \\
(Self-Directed)
\end{tabular}

\subsubsection{Objective 2: Severity of Student Behaviour}

The study aimed to challenge the claim in the literature that it is a student's presentation or severity of behaviour that causes stigmatisation leading to discriminatory approaches. Is EI the greatest influence over how students with EBDs are perceived and treated, or are there stronger indications that it is in fact the student's presentation (e.g., violent behaviour) that has the greatest influence over stigmatisation? Is a student's level of difficult or challenging behaviour a stronger predictor of teacher helping behaviour than EI? Is perceived student risk a factor influencing teacher helping behaviour irrespective of a teacher's disposition? It was predicted that these environmentally conscious factors, such as student behaviour severity and perceptions regarding the level of risk, would not significantly influence behavioural approaches for teachers with higher EI. The hypotheses relating to the severity of student behaviour and the level of perceived risk are displayed in Tables 2 and 3. It was additionally explored as to whether teachers' causal perceptions of the student's presentation related to their perception of the student's level of control and their own level of personal responsibility.

Table 2. Predicted outcomes of experimental groups (high vs. low behavioural severity).

\begin{tabular}{ccccc}
\hline Teacher Level of EI & Student Experimental Groups & & Teacher Behavioural Outcome \\
\hline High EI & $\rightarrow$ & $\begin{array}{l}\text { High Behaviour Severity } \\
\text { Low Behaviour Severity }\end{array}$ & $\rightarrow$ & Supportive Helping Behaviours \\
\hline \multirow{2}{*}{ Low EI } & $\rightarrow$ & $\begin{array}{l}\text { High Behavioural Severity } \\
\text { Low Behavioural Severity }\end{array}$ & $\rightarrow$ & $\begin{array}{c}\text { Punitive Behaviours } \\
\text { (Discriminatory) }\end{array}$ \\
\hline
\end{tabular}

Table 3. Predicted outcomes of teachers based on their level of perceived risk of student violence.

\begin{tabular}{cccc}
\hline Teacher Level of EI & Teacher Level of Perceived Risk & Relationship & Teacher Behavioural Outcome \\
\hline Low EI $\rightarrow$ & Higher Perceived Risk & $(+)$ & Higher Punitive Behaviours \\
\hline High EI $\rightarrow$ & Lower Perceived Risk & $(-)$ & Higher Helping Behaviours \\
\hline
\end{tabular}

\subsubsection{Objective 3: Ideal Traits}

Most importantly, the study aimed to determine, what are the ideal EI traits that cultivate the most effective approaches towards students with EBDs?

\section{Materials and Methods}

\subsection{Participants and Procedure}

Research and ethics applications were approved by the Federation University's Human Research Ethics Committee and related Victorian education/school departments (Ref: A14-156, 12 February 2015). A letter was mailed to the principals of 1803 Victorian primary and secondary mainstream schools, inviting their qualified teaching staff to participate in the study. Three hundred and fifty-nine teachers responded to the survey. The 
sample size obtained was 261 teachers. Ninety-eight responses could not be used for further data analysis due to incomplete surveys, questions and non-teacher responding. The sample slightly under-represented males and slightly over-represented females when compared with the total population of teachers in state schools in Victoria. Out of all respondents, $78.5 \%$ were female and $21.5 \%$ male.

A survey experimental method was employed through the use of vignettes, which is considered to be one of the most common methodological approaches recorded by researchers relating to attribution theory and stigma. Teacher respondents were randomly assigned to one of two hypothetical vignette conditions, via a nominated school representative evenly distributing one of two surveys to teachers via email. Teachers were not informed that there were two behavioural comparison groups. Surveys were completed by volunteering teachers through a de-identified internet survey site.

Teachers were asked to read a hypothetical vignette scenario of a student and were asked to imagine the student was in their class. The scenario described a student with an emotional behaviour disorder. The term student presentation was carefully selected for the questionnaire to avoid pre-labelling the student. The two scenarios varied in their intensity of the student's challenging or difficult behaviour (low- and high-behaviour-severity scenarios). Both vignettes were identically presented except for one varied condition: The first vignette (high behaviour severity) included an additional paragraph that described a student with an EBD who had a propensity towards physical aggressiveness and violence. The second vignette (low behaviour severity) only peaked to a verbally aggressive presentation. The presence and absence of the physically aggressive/violent paragraph was the variable that was considered to measure any differences in outcomes between the two teacher experimental groups.

\subsection{Measures}

\subsubsection{Trait Emotional Intelligence Questionnaire (TEIQue)}

Teachers were administered the Trait Emotional Intelligence Questionnaire [93]. This scientific measurement instrument is based exclusively on trait EI theory and reflects teachers' self-perceived abilities and behavioural dispositions. Petrides' [93] trait EI model purports to incorporate and expand on EI-related concepts into a general framework made up of 15 trait facets. In addition, this model categorises individual facets into four broader factors, well-being, self-control, emotionality and sociability, with two auxiliary factors not being accommodated in the four key factors (see Table 4). The 153 questions presented to teachers relate to these 15 trait facets.

Table 4. Petrides' (2009) 15 individual trait facets of the trait EI model positioned with reference to their corresponding factor.

\begin{tabular}{ccccc}
\hline Well-Being & Sociability & Emotionality & Self-Control & Auxiliary Factors \\
\hline Optimism & Emotion Management & Relationships & Stress Management & Self-Motivation \\
Happiness & (in Others) & Emotion Expression & Low Impulsiveness & Adaptability \\
Self-Esteem & Assertiveness & Emotion Perception & Emotion Regulation & \\
& Social Awareness & Empathy & & \\
\hline
\end{tabular}

The TEIQue is the only psychometric instrument that comprehensively covers all constructs of trait EI [94]. Due to its large number of facets, the TEIQue was appropriate to use for profiling and identifying the specific teacher traits. The internal consistency results based on the current United Kingdom (UK) normative sample $(\mathrm{n}=1721)$ was derived from the TEIQue Technical Manual [93]. The TEIQue variables demonstrated adequate-to-high Cronbach alpha values that were stable across gender and age [93]. The TEIQue Technical Manual provides statistical evidence for the validity of the TEIQue, as do many other published studies undertaken recently. Petrides demonstrates strong evidence for conceptual, criterion, concurrent, discriminant, incremental, predictive and construct validity [93]. In addition to the quantitative interpretation of the teacher scores that are made for each EI trait facet, Petrides presents qualitative interpretations. 
Petrides' Trait Emotional Intelligence Questionnaire [93] employs a 7-point Likert scale. It is widely accepted that 7-point scales are best psychometrically for reliability maximisation and discriminability [93].

Exploratory factor analysis methods were performed to determine the validity of Petrides' TEIQue full-form instrument and to find the best fit of the teacher research data. The final method chosen for the current study's investigation resulted in some eliminated and adapted trait scales, leaving 65 items that comprised 12 trait facets. These newly adapted trait facets showed adequate reliabilities with Cronbach alpha coefficients greater than 0.7. Significant relationships (most correlations above 0.8 ) were also found between Petrides' original trait facets and the newly revised trait facets at the $p<0.01$ level.

\subsubsection{Teacher Attribution Model Survey (TAMS)}

The Teacher Attribution Model Survey was the instrument developed primarily to measure the attribution factor stage within the EI Process Model of Stigmatisation (EPS-Model). The TAMS consisted of a demographics section, cognitive scales, affect scales and behaviour scales. It also consisted of causal attribution factor scales. Stigmatisation was measured by the cognitive reactions that teachers had regarding a student's presentation. A teacher's willingness to help the student (behaviour scale) was the measure used to determine level of discrimination and likely resultant behavioural approach.

The demographics section of the TAMS (Section A) elicited background information from the participants, including age, gender, highest level of education achieved, years of teaching experience, school type, subjects taught and year levels taught. Demographics were responded to using multiple-choice format, where the respondent was instructed to tick the appropriate box.

For the attribution variables, a 7-point Likert scale asked respondents to indicate the position on the scale that their views would most likely reflect: the extent to which they think they would feel the specified emotion and the extent to which they would help or want to punish/avoid the student (from $1=$ not at all, to $7=$ very much).

The cognitive component of the attribution model consisted of four underlying factors: perception of student (student control), perception of self (personal responsibility/control), self-efficacy and perceived risk. The affect component consisted of two separate scales labelled compassion and negative affect. The behaviour component of the attribution model consists of two underlying factors, namely likely helping behaviour and likely punitive behaviour.

The causal attribution section consisted of a list of 19 causal factors that were categorised into four broad areas, family environment factors, student factors, teacher factors and school factors, many of which were selected from Poulou and Norwich's factor list [3]. Teachers were asked to indicate the extent to which they thought each item was likely to be the cause of the student's presentation in the vignette. They were asked to choose only one number on a 1-to-5 Likert scale for each factor/statement, with 1 being a very unlikely cause to 5 being the most likely cause.

The underlying structure of each of the factor scales within the attribution model questionnaire for the sample was also explored using factor analysis (FA) and principal components analysis. All the data used were suitable for FA. Inspection of the correlation matrix revealed the presence of many coefficients above 0.3 , the Kaiser-Meyer-Olkin values exceeded 0.6 and Bartlett's test of sphericity reached statistical significance, supporting the factorability of components in the correlation matrix. Almost all of the original items and scales were retained, as predicted.

The researcher expected that the affect items would cluster into self-directed and other-directed affect, as consistent with Poulou and Norwich [3]; however, they were found to cluster into two groups relating to compassion and negative affect variables. Compassion is 'the feeling that arises in witnessing another's suffering and that motivates a subsequent desire to help. This definition conceptualizes compassion as an affective state defined by a specific subjective feeling, and it differs from treatments of compassion as an 
attitude ... ' [95]. Negative affect captures negative emotional states that teachers report experiencing towards students with EBDs.

\subsection{Statistical Analysis}

\subsubsection{Analysis 1: Attribution Model Relationships}

Statistical procedures were performed to understand the teacher data and their suitability for analysis. One-sample Shapiro-Wilk tests indicated non-parametric analyses were required. Boneau, in Thomas and Rose [96] (p.172), proposed that 'the violation of the assumption of normal distribution generally has little effect on the values of parametric tests'. This was confirmed to be the case in the current study, where the correlational data, regression data and independent $t$-tests indicated the same significant statistical findings, whether parametric or non-parametric methods were used. Means and standard deviations were computed for all metric variables. This helped to locate significant relationships between attribution and EI variables. Pearson's correlation coefficient (r) was computed as the main correlation measure throughout the study. Only significant correlations higher than 0.20 were selected for further analysis.

EI trait correlations demonstrated the (theoretical) independence and interrelation of each trait facet variable. The traits are generally low to moderately correlated, suggesting that the facets are independent of each other (measuring different theoretical concepts) yet are also interrelated, as would be necessary for personality scales. The trait facets also generally show (low to high) moderate correlations with global EI, demonstrating shared dependency and contribution to a person's overall EI.

It needed to be determined whether the attribution model was actually measuring the processes that it purported to measure with this sample/context. That is, that likely punitive/helping behaviour is dependent on affect, which is dependent on cognition. Correlational relationships were explored to determine significant relationships. Multiple regression statistics were computed to indicate predictive variables, as well as variance $\left(\mathrm{R}^{2}\right)$, beta and T statistics.

Exploratory regression analyses of the attribution model factors were performed to demonstrate possible relationships outside of the hypothesised model. Pathway analysis extended on these relationships to confirm the directionality of the proposed model and the indirect influences on the model stages. A new direction was tested where cognition is dependent on affect and likely behaviour (punitive/helping) is dependent on cognition.

Path analysis models were computed using AMOS (version 23). As the hypothesised model did not reach statistical significance, a series of hypothesised and revised model designs were statistically tested where path analyses eventually identified the pathway and variables that most strongly associated with the outcome measures (helping and punitive behaviours) and the influence of EI on these measures. A maximum likelihood chi-square estimation method was used to test each directional pathway, as well as several bestfit indices.

\subsubsection{Analysis 2: Student Behaviour Severity}

Differences between the two experimental groups were explored in relation to their levels of global EI and individual EI traits. This was to ensure that EI was a controlled factor and that there were no differences in EI between the two groups that could account for any statistical effects found in the following analyses. Independent $t$-tests (Pearson's r) were used to determine whether significant differences existed between the two experimental groups (behaviour severity-low vs. high) on all major constructs.

The mean ranks test $(\mathrm{U})$ helped determine whether there were any significant effects that the different vignettes may have elicited between the two groups. Comparisons between mean ranks of high- and low-severity groups were calculated for the teacher's (1) perception of the student, (2) perception of self, (3) self-efficacy, (4) perceived risk, (5) negative affect, (6) compassion and likelihood of (7) helping and (8) punitive behaviour. Independent $t$-tests compared and confirmed any undetected differences in statistical outcomes. 


\subsubsection{Analysis 3: Ideal Traits}

Teachers with extreme and least favourable traits were specifically identified so that profiles could start to be developed for the Assessment Screen for Emotionally Intelligent Teachers tool. The term least favourable refers to those teachers whose scores indicate the most negative consequences or harmful outcomes for either themselves or students. Extracted profile groups (EPGs) were identified based on their high or low scores (within the top or bottom 25th percentile of scores) on all the attribution model variables within each related pathway previously identified (direct and non-direct). This method helped identify and cluster teachers whose scores on the attribution model pathway were most related to lower helping and higher punitive outcomes.

Each EPG was compared with the remaining teacher population group using independent $t$-tests to ensure the two groups were statistically distinct and unique across relevant attribution pathway variables, as was the purpose of extraction. Other attribution variables were explored between the two groups for supplemental information about any statistically significant disparities.

Once EPG groups were established, their levels of trait EI were compared with the rest of the teacher population using independent $t$-tests. Significant differences found for some EI traits highlighted the presence and impact of EI on each attribution variable within that particular pathway. EI traits found to vary significantly were used for further analysis that led to the most ideal outcome/profile.

Cut-off criterion analysis that related to the tool development is outside the scope of this article. Once trait EI cut-off scores were created, hypothesised predictions were tested. The total population of teachers was divided into two groups: those who scored above and below the cut-off scores in relation to EI. Using independent $t$-tests, it was determined whether the two teacher groups, who differed in their levels of EI, were still able to predict (the originally identified) variance across the attribution model variables-affect, cognitive and behaviour. Significant differences between the two groups confirmed the ability of EI to predict helping outcomes (without having to specifically measure a teacher's affective and cognitive processes).

\section{Results}

Following a series of hypothesised and exploratory tested model designs, path analyses successfully identified the pathway and factors most strongly associated with the outcome measures (likely helping and punitive behaviours) and the influence of EI on these measures. The directionality of the pathway, as well as other important indirect associations, were considered. The possible differences between the two experimental groups in relation to the newly proposed EPS-Model were also explored.

\subsection{Results 1: Attribution Model Relationships}

The researcher proposed a new EI Process Model of Stigmatisation (EPS-Model) as a way to measure teacher reactions through an affective-cognitive-behavioural sequence, rather than a cognitive-affective-behavioural sequence. The originally hypothesised directional model was not supported. The proposed statistical model is presented below in Figure 2.

The model statistics indicated a non-significant chi-square result: $\chi^{2}=10.011, \mathrm{df}=13$ and $p=0.693$. All the other best-fit indices created an almost perfect solution: Root Mean Square Error of Approximation (RMSEA) $=0.000$, Goodness of Fit Index $(\mathrm{GFI})=0.990$, Comparative Fit Index (CFI) $=1.00$, Tucker Lewis Index (TLI) $=1.01$ and Standardized Root Mean Squared Residual $(S R M R)=0.0215$. All variables significantly correlated at the $p=<0.05$ level.

The values in the squared multiple correlations in Table 5 represent the percentage of variance (multiple R-squared value) in the dependant variable explained by the model. Forty-eight percent of the variance in likely helping behaviour is explained by the variables 
in the model. The corresponding value for likely punitive behaviour shows that $37 \%$ of variance is explained.

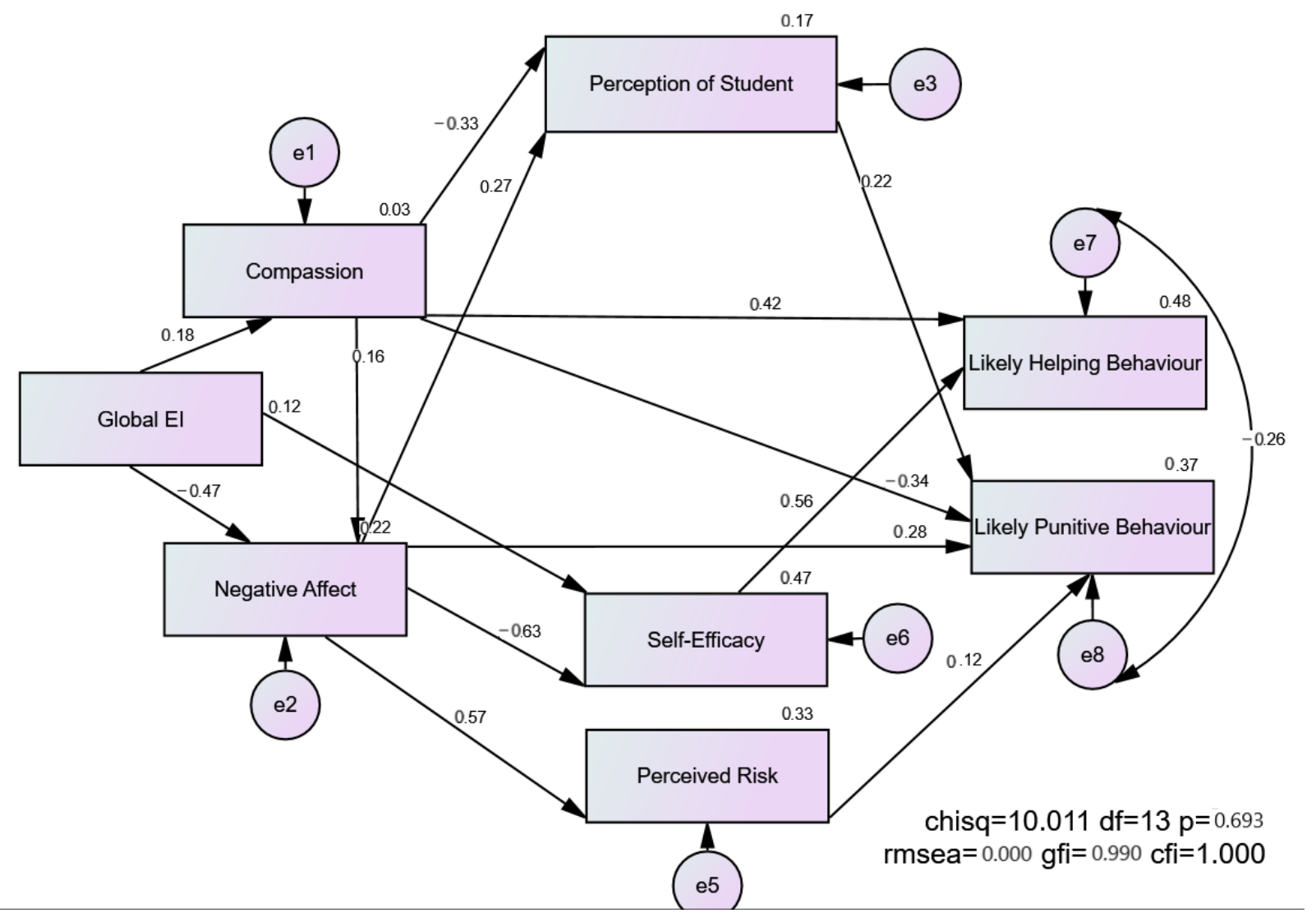

Figure 2. Pathway statistical model of proposed EI Process Model of Stigmatisation (EPS-Model).

Table 5. Squared multiple correlations of final model (group number 1-default model).

\begin{tabular}{cc}
\hline Model Variables & Estimate \\
\hline AffectCOMPASS_TOTAL & 0.033 \\
AffectNEG_TOTAL & 0.216 \\
CogSTUDENT_TOTAL & 0.166 \\
CogSELFEFFICACY_TOTAL & 0.471 \\
CogPERCEIVEDRISK_TOTAL & 0.330 \\
HELP_TOTAL & 0.481 \\
PUNITIVE_TOTAL & 0.366 \\
\hline
\end{tabular}

Within this new EPS-Model, a number of directional pathways were identified, where likely helping and punitive behaviour outcomes were dependent on teacher EI levels, as hypothesised. The main hypothesis was supported in that teachers who have higher EI are less stigmatising and punitive with a higher likelihood of using effective helping behaviours/approaches. EI did not directly predict helping or punitive behaviour but relied on the affective and cognitive factors to translate the unconscious EI processes into either helping or punitive behaviour. A number of possible pathways extracted for teachers resulted in either likely helping or punitive behaviours. These were categorised into direct and indirect pathways.

\subsubsection{Direct Pathways}

Generally, EI influenced affect, which directly influenced behaviour. Specifically, higher EI levels led to teachers experiencing lower levels of negative affect $(\beta=-0.47)$, 
which led to lower punitive behaviour towards the student $(\beta=0.30)$, and vice versa. Higher EI levels also led to higher compassion $(\beta=0.18)$, which led to higher helping $(\beta=0.42)$ and lower punitive behaviour $(\beta=-0.34)$.

\subsubsection{Indirect Pathways}

In the current model, teacher cognitions also acted as mediators between EI, affect and helping, which did not appear to influence or change the course of action for teachers. Higher EI produced higher perceived confidence (self-efficacy) in teachers towards managing the student $(\beta=0.12)$, which led to higher helping behaviour $(\beta=0.56)$.

The causal attribution factors provided no additional statistical significance to the model, nor did they have any bearing on predicting behaviour. The personal responsibility variable was also removed as it did not relate to any helping outcomes.

Teachers with higher compassion towards the student perceived the student to be less responsible for their behaviour (perception of student: $\beta=-0.33$ ), which resulted in lower punitive behaviour $(\beta=0.22)$. Higher compassion also had a directional link to higher negative affect levels $(\beta=0.16)$, which led to higher levels of punitive behaviour.The level of negative affect was also a predictor of perceived risk $(\beta=0.57)$ and high perception of student responsibility/control $(\beta=0.27)$, which both showed on separate paths leading to likely punitive behaviour $(\beta=0.12 ; \beta=0.22)$. Compassion featured on two conflicting paths, which is not theoretically justified in this article; however, it is suggestive of the possible presence of compassion fatigue (where high compassion related to high negative affect). This influenced likely helping or punitive outcomes.

\subsubsection{Summary of Different Pathways Identified in the Proposed Model}

Six variable pathways were identified from EI to likely behaviour, as determined through the new proposed model (Table 6).

Table 6. Six different pathways identified in the proposed EI Process Model of Stigmatisation (EPS-Model).

\begin{tabular}{cr}
\hline & Direct Pathways (EI $\rightarrow$ Affect $\rightarrow$ Behaviour) \\
\hline Pathway 1 & Negative affect was directly related to likely punitive behaviour. \\
\hline Pathway 2 & Compassion was directly related to both likely helping and punitive behaviours. \\
\hline Pathway 3 & Indirect Pathways (EI $\rightarrow$ Affect $\rightarrow$ Cognitive $\rightarrow$ Behaviour) \\
\hline Pathway 4 & Compassion $\rightarrow$ Perception of Student Responsibility $\rightarrow$ Likely Punitive Behaviour \\
\hline Pathway 5 & Negative Affect $\rightarrow$ Self-Efficacy $\rightarrow$ Likely Helping Behaviour \\
\hline Pathway 6 & Negative Affect $\rightarrow$ Perceived Risk $\rightarrow$ Likely Punitive Behaviour \\
\hline
\end{tabular}

\subsection{Results 2: Student Behaviour Severity}

No significant differences were found between experimental groups for each EI trait and global EI. This suggests that the student's behavioural presentation did not have any significant effect or influence on a teacher's EI. EI also did not account for differences found between experimental groups in relation to the attribution model variables. Therefore, EI can be considered an effectively controlled independent variable.

Significant differences were found between the two behaviour severity groups in relation to self-efficacy $(\mathrm{t}(249.36)=-2.62, p<0.01)$, perceived risk $(\mathrm{t}(255)=4.37, p<0.01)$ and compassion $(\mathrm{t}(255)=3.64, p<0.01)$. It was assumed that behaviour severity manipulation of the hypothetical student was the influencing factor where significant differences were found between the two experimental groups. Regardless of this finding, no significant differences were found between the two groups in relation to likely helping and punitive behaviours. So, despite the identified effect of student behaviour on teachers' cognitions, it still did not affect teachers' likely behavioural outcomes. As predicted, teachers higher in 
EI were still more likely to indicate supportive helping behaviours and teachers lower in EI were still more likely to reflect more punitive or discriminatory behaviours, despite the level of behavioural severity of the student with an EBD.

The possible differences between the two behaviour severity groups (low and high behaviour severity) were explored in relation to the newly proposed EPS-Model to help understand the possible influence of student behaviour on the model's processes. These models may not have been statistically reliable due to their small sample size; however, they did provide useful additional conceptual information in trying to understand the effects of the different severity levels of student behaviour and EI.

Only the high-behaviour-severity model found a directional relationship between the teachers' level of perceived risk and punitive behaviour, suggesting a link was only present when the hypothetical student's behaviour indicated a physical risk. It also revealed that when the student's behaviour is high in severity and physically threatening, high compassion levels in teachers can lead to some teachers also experiencing high levels of negative affect. No statistically significant relationship was found between perceived risk and punitive behaviour, nor between the compassion and negative affect variables, nor global EI and self-efficacy for the low-behaviour-severity group. Therefore, compassion did not lead to teachers experiencing high levels of negative affect when the student behaviour was only mild and not physically threatening (low-behaviour-severity group). When EI was considered in this equation, it was still those teachers lower in EI who experienced high negative affect, leading to high perceived Risk and likely punitive approaches. The hypothesis relating to perceived risk was supported in that teacher perception of high risk led to punitive approaches; however, this was only the case for those teachers exposed to the high-behaviour-severity group and who had lower EI. EI was still the dominant factor in teacher perception and behavioural outcomes, despite the threat. This also supported the new EPS-Model as being predictive when applied to extreme threatening behaviours.

The causal attribution factor scores (student, teacher, school and family factors) were compared using related samples $t$-tests to determine whether there were significant differences in what teachers perceived to be the main cause of the student's behaviour. Family factors were perceived to be the most significant cause for the students' behaviour, followed by school factors and then student and teacher factors. No significant differences were found between the two teacher groups in relation to their perceived cause of the student's behaviour. Perception of student and perception of self were the only variables found to significantly relate to some causal attribution item factors with an effect size greater than 0.20 . The perception of student (student responsibility/control) variable related to the item the student is being purposely manipulative. The perception of self (personal responsibility) variable related to the items teaching style, teacher personality and teachers' inappropriate manner.

\subsection{Results 3: Ideal Traits}

The EI Process Model of Stigmatisation provided insight into the processes behind teacher helping behaviour. The six proposed pathways were used to statistically identify the profiles of teachers whose scores were most related to lower helping and higher punitive outcomes and what their specific EI traits were that steered them through the psychological processes to use the most effective approaches. EI trait levels within each profile predicted differences in how teachers are likely to react emotionally, cognitively and behaviourally. Those who did not meet the final ideal criterion level cut-offs were more likely to show responses indicative of stigmatisation and discrimination against students with EBDs. The ideal profiles are presented in Appendix A.

\section{Discussion}

Contrary to the attribution model proposed by Corrigan [36], the new EPS-Model purports that behaviour is mediated by an affective-cognitive process rather than a cognitiveaffective process, as was not hypothesised. EI achieved predictive behavioural patterns in 
two ways, as already reported (Figure 3). The first way, through what the author labels direct pathways, consists of an affective-behavioural process. The second, through indirect pathways, involves an affective-cognitive-behavioural process. These pathways both confirmed the hypothesis that EI can predict behavioural outcomes, as measured through emotional and cognitive pathways. The findings are not considered unusual as other researchers have found inconsistent results or partial support regarding the directionality or placement of variables in the attribution model [92].

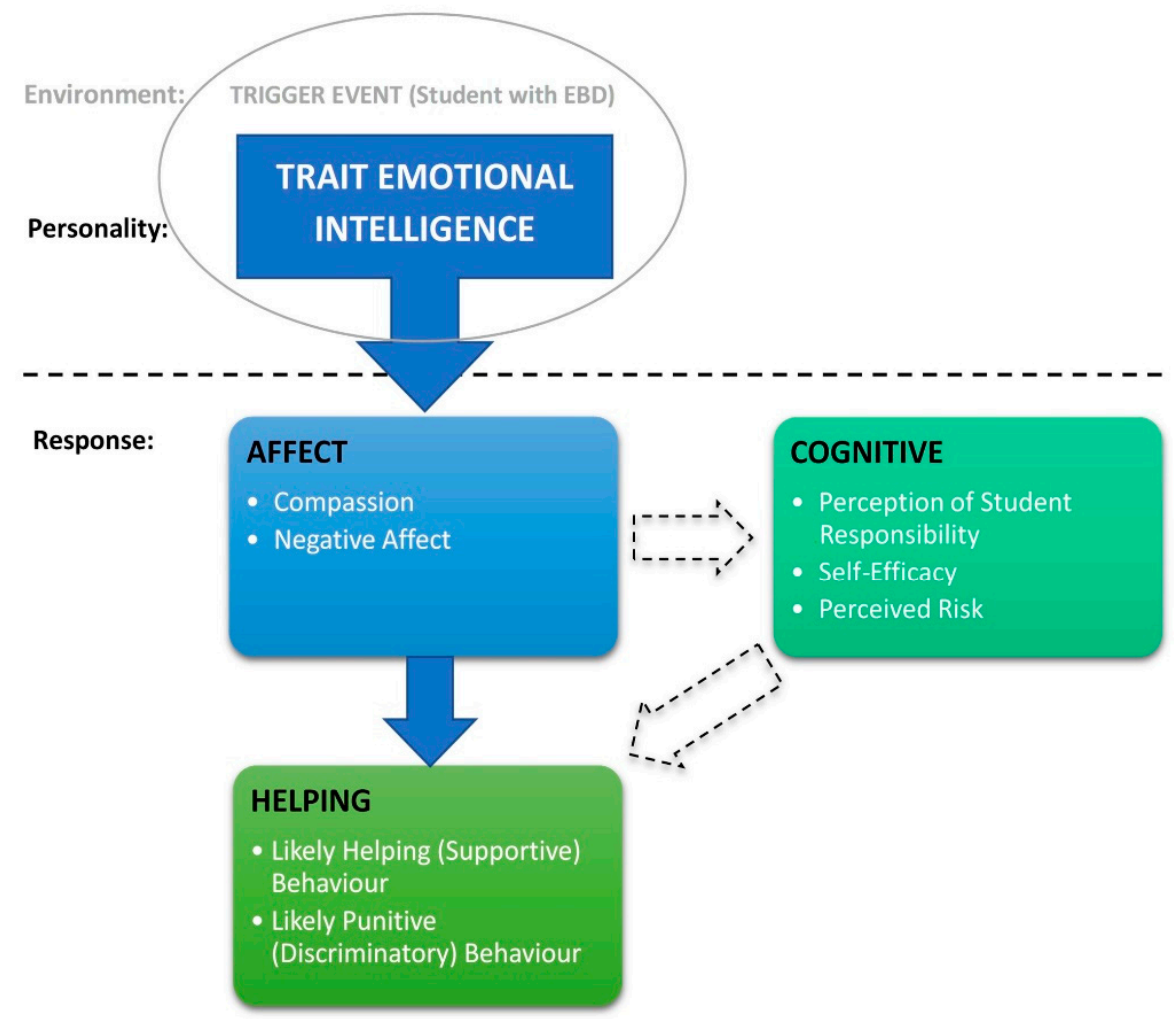

Figure 3. Trait EI Process Model of Stigmatisation (EPS-Model) illustrating direct and indirect pathway sequences.

It is asserted that affect, as the direct product of EI, is more important than cognition for predicting behavioural outcomes. It is generally suggested that EI, through its resultant affective states, is a stronger influence of desirable helping outcomes and can either bypass or bias conscious thought processing regarding oneself or the environment. This is consistent with theories that suggest affective responses act as information on which to base decisions, as well as influencing behavioural responses [70]. In this way, affect has tended to direct thought content towards the way one is feeling. Emotions can also distort decision-making and evaluative processes [69], suggesting that the best approach towards EBD students does not primarily occur via conscious thought processing.

Having background information, judgements or education about what causes a student to behave the way that they do was found to be irrelevant in teachers' likely course of action. This suggests that despite having knowledge of a problem, it does not guarantee a solution. Helping outcomes were still driven by EI and affect, irrespective of the perception of cause, the risk or who may be more responsible or to blame. Perhaps higher EI and lower negative affect enable teachers to naturally find a solution and solve problems rather than focus solely on the individual within the context and try to decide who is responsible or to blame. Most practical strategies and techniques towards working with EBDs in any role require particular cognitive and/or educational skills but fail to recognise the innate unconscious processes that naturally present. It is these processes that are felt by another person during formal strategic or informal interaction, more so than what is practically 
being communicated or implemented. These are rarely overtly identified as the potential effective element in evaluating any successful interactional outcome. Building engagement, or a rapport, is recognised and discussed in mental health professions; however, it is unclear as to what this measurably looks like. It is clearly not just thinking about and stating what is to be expected in the relational role.

A teacher's approach towards helping a student with an EBD is not dependent on how severe or challenging the student's behaviour presents, as consistent with some studies [3,7]. While student behaviour generates stigmatising cognitive reactions, the behavioural approach is still likely to be positive for those teachers with higher EI. A teacher's EI still proves to be the primary predictor of positive behavioural outcomes, regardless of a student's level of problematic behaviour or the teacher's reaction to this environmental challenge. This is another example of how cognitions do not significantly influence behaviour.

A new notion emerged from the results, which suggested that when the student's behaviour is high in severity and/or physically threatening, teachers are at risk of compassion fatigue (high compassion levels leading to high levels of negative affect). Although student severity was found to put teachers at greater risk of this phenomenon, it was the level of EI that was the deciding factor as to how teachers emotionally coped with the behaviour, and their resultant approach towards the difficult student presentation. Self-preservation and resilient factors are certainly required. When a person feels stressed and anxious or has poor mental health (such as experiencing high levels of negative affective states), they are likely to feel more vulnerable and overwhelmed and possibly perceive situations to be more negative, harmful and amplified than what they actually are. As already suggested, affective states can distort decision-making and evaluative processes. Being able to cope and regulate one's own emotions is reliant on a person's EI. All of these factors are relevant to understanding the most effective approach towards EBDs.

The predictability of helping behaviour has probably been shown to vary in studies as they have failed to measure other unconscious factors and processes occurring within a person. The most effective approach towards students with EBDs is one that is natural and uses the already innate resources of teachers. It is not unhelpful to draw on educational sources and training in order to develop an understanding of interventions and approaches towards students with EBDs; however, these factors are less important in whether the practical approach is likely to be successful or not.

Identifying the significant traits responsible for each directional pathway to helping assisted in determining which EI traits lead to greater supportive or discriminatory behaviours. Through the analytical process, it was revealed that it is not individual EI traits alone that produce the most effective outcomes, but rather a combination or cluster of EI traits that interact and work together to produce the most desired approach. This idea is considered common in psychology in understanding a person's personality as a whole and how different traits may complement each other to reveal a person's true presentation, symptomology or functioning. As an example, two teachers may have similar levels of self-esteem, but if one is low in other important traits, such as empathy and assertiveness, this teacher may not be able to handle the emotional demands of a situation as well as the other teacher, who has higher EI. Searching for just a few ideal traits or characteristics now appears too simplistic. To think that a solitary trait or single variable could have such significant effects on students and classroom outcomes is unrealistic. In reality, humans are multi-faceted. EI, like personality, is much more complex in nature when referring to its behavioural effects. In human psychology, the same behavioural outcomes are not always accomplished or reached the same way by every individual. There are often different personality codes or trait combinations that could lead to similar actions or consequences and, in this case, approaches towards a matter. The identified trait EI profiles are presented in Appendix A.

The ideal traits are defined in the current study as those EI traits that have been found to lead teachers to higher levels of likely helping behaviour. It is these innate 
psychological attributes underlying likely helping that are expected to create the most appropriate environment for any student. These psychological attributes, known as trait EI, are conducive to the classroom environment for the reason that they work to eliminate likely stigmatising attitudes and discriminatory behaviour, which then helps to promote better teacher-student relationships, student well-being, teacher well-being, student academic achievement and reduced behavioural problems $[7,9,10]$.

The resultant ideal EI traits that were discovered enabled teachers to perceive the student in more compassionate ways, whilst keeping their feelings in balance. They also related to higher levels of teacher self-efficacy and to lower levels of perceived student responsibility/control, which has been proven in research to relate to more positive student outcomes. Through the challenges faced with students with EBDs, teachers who possess these ideal traits should be more able to regulate their emotions as a way to keep their own experience of negative affective states at minimum and avoid longer-term stress and burnout and the resultant negative impacts on those around them.

As a result of developing these new EI trait profiles, a new view of the definition of emotion regulation is proposed by the researcher that is recommended for use in future studies. During factor analysis of Petrides' TEIQue items, his emotion regulation trait was removed from the current study's analysis because his emotion regulation items were too interrelated with many of his other proposed trait scales and could not be discretely statistically measured. This also suggests that effective emotion regulation is present across a person's combinations of traits. To have control over one's emotions (self-regulation) in this study's context is to not discriminate, despite one's stigmatising cognitions (whether intentional or not). The ability to not discriminate is driven by a specific group of EI traits working together to take charge of a behavioural outcome. Therefore, emotion regulation is thought to be concerned with how a person manages their way through situations, just like that found in the EI trait pathways, as a process of regulation across affective, cognitive and behavioural levels. Emotion regulation cannot be determined by asking teachers directly whether they can control their emotions, like Petrides' TEIQue does, but rather, it is the overall effects and outcomes of the unconsciously measured approach that indicate who can and cannot effectively regulate. In considering all of the above factors, the most effective approach towards helping students with EBDs stems from predisposed traits that influence positive emotional regulatory reactions towards others.

In relation to teacher demographics, all trait levels remained stable across teacher age and experience except for the younger and less experienced teachers (within their first five years of teaching) who were found to be significantly higher in pessimism, lower in self-motivation and higher in likely punitive behaviour. The possibility of some EI trait levels not being fully developed in individuals until they reach an age of maturity is not a new concept. These differences within the younger age group in comparison could also be a reflection of the type of teachers who are able to remain in the field long term versus the many different new teaching personalities who have not yet found their niche. Future historic-cultural or generational studies may provide further insight into these patterns based on teachers' own relational experiences during emotion developmental stages.

Training is likely to be ineffective for improving a teachers' EI, as it is considered innate; hence, the easiest and most effective solution is an initial selection process. Depending on a professional's EI profile, they may benefit from being placed into roles to which they are more suited. This may mean engaging with students who may be the least affected by negative reactions or whose behaviour does not trigger stress or negative reactions in professionals. Such students would need to be emotionally and socially welladjusted, resilient to stress and anxiety and not easily influenced by the emotions of others. Professionals lower in EI may benefit from non-challenging or demanding students in their classrooms or clinics, if possible. Despite their qualifications and training, it is unlikely that all professionals working with EBD students possess the requisite traits to be able to naturally implement the most effective emotional approaches through their regularly implemented practical strategies and techniques-hence the need for a measure to identify 
those who possess these effective EI traits for best-quality practice and professional and EBD student well-being.

\subsection{Implications}

This study may have implications for teachers, psychologists, psychiatrists and counsellors whose profession it is to engage with students with EBDs. It is apparent that the study of EI has a role to play in developing an understanding of professionals' unconscious behaviour towards students and should become a part of ongoing research endeavours. It provides a basic awareness of the processes that may occur and that easily go un-noticed. It lends important evidence to the role of EI in predicting behaviour and performance through a directional model. In particular, this may be one of the first studies to demonstrate that EI traits, within a personality framework, can actually predict ineffective or discriminative behaviour via an affective-cognitive attribution pathway.

This study presents and suggests a new methodology as a way to capture and assess invisible (teacher) contributors to performance, as well as these unconscious processes of stigmatisation towards students. The EPS-Model can serve as an effective framework from which to study and statistically assess the directionality of EI as a predictor of behaviour. To determine the conceptual generalisability of the EPS-Model and its validity, further studies need to be conducted. The current study demonstrated the numerous benefits and limitations of Petrides' TEIQue. It also provided researchers with additional considerations and options regarding the statistical use of the TEIQue and its contextual application.

The study also promotes and advocates for the practical implementation of a highly desirable criterion for professionals to be employed or used for specific duties on the basis of their level of EI, not just on their experience, education and surface presentation, as a whole workplace approach. The shift in focus to innate EI traits as the primary influence behind stigmatisation and discrimination has created a new direction and novel interpretation of the processes behind stigma and within education discriminatory studies. The level of emotional support from teachers affects not only their interactions with students but plays a significant role in students' adjustment, development, emotional well-being and academic achievement. The topic and concept of EI is still in its infancy, which suggests that the findings herein should help the concept to expand further. It should also assist researchers in appreciating the concept and understanding its possible functions and context applications more thoroughly.

\subsection{Limitations}

The teacher sample response rate was only a small representation of the actual teacher population in Victoria. However, EI traits are purported to be unique to each individual rather than contexts. A personality framework assumes validly accepted generalisability across contexts [97,98], [99] (p.7). Petrides proposed, 'As a measure of emotion-related self-perceptions, the TEIQue can provide vital and consistent cross-situational information about an individual's personality and behavior ... The TEIQue transcends the arbitrary boundaries that restrict the utility of inventories assuming that people's personality changes from context to context' [99] (p. 7).

There was a large percentage of surveys that could not be used for further analysis as they were incomplete. The instrument required a comprehensive trait analysis for the current study's goals, where the length of the survey is a limitation of most personality assessment measures. Self-report measures are problematic due to social desirability, response set patterns and lack of self-awareness. Where social desirability bias is operative, the data may underestimate the true extent of stigmatisation in the study's findings [100], especially for the punitive question items.

Finally, vignettes are only hypothetical abstractions from real-life experiences [100], suggesting that teachers are not in the presence of a real student. Willner and Smith [91] proposed that future research should address the issues of the limited reliability of the vignette-based methodology commonly used in attribution studies. However, Ajzen and 
Orbell et al. [101,102] support the position that intentional behaviour is closely associated with actual behaviours and has a high degree of acceptable predictive ability. The researcher chose to operationalise helping behaviour as likely helping behaviour in order to allow for this probability. Observational methods could have been used to assess teachers' actual behaviours rather than reported behaviours; however, teachers' cognitions or EI traits needed to be measured through self-reporting, as the teachers themselves were the only ones who could access this type of information. The research was primarily about teachers' subjective and individual experiences.

\section{Conclusions}

Trait emotional intelligence, through the current study, has proven to be valuable as an innate trait-based approach for effectively supporting and interacting with EBD students via its related psychological mechanisms. EI and its related affective-cognitive processes plays a significant role in preventing and managing disruptive behaviour and mental health problems through its unconscious processes, which can be felt or sensed by others but not necessarily recognised. Some individuals are predisposed to higher levels of the most ideal EI traits, and they will most likely have more desirable and positive outcomes in engaging with EBD students compared to those lower in EI. It is not a student's behaviour that causes inequitable behaviours towards them, but rather, the ability of the observer to regulate their own emotions and cope with the student's complex presentation. The best practice lies within the facilitator rather than with an emotionally detached practical strategy.

The study of personality EI has an important role to play in understanding professionals' unconscious behaviour towards students and should continue to be explored. It has also initiated a new focus within discrimination studies. It is recommended that the newly developed ASET tool be practically applied for teacher selection or recruitment processes in universities and schools. Future studies should use the ASET and the EPS-Model to test for and increase their validity. Finally, it is recommended that the current study's methodological framework and instrument be investigated within other contexts and tested for its relationships with other psychological measurements.

Funding: This research was supported by the Australian Government Research Training Program (RTP) Fee-Offset Scholarship through Federation University, Australia.

Institutional Review Board Statement: The study was conducted according to the guidelines of the Declaration of Helsinki and approved by the Federation University's Human Research Ethics Committee (approval no. A14-156 on 12/02/2015).

Informed Consent Statement: Informed consent was obtained from all subjects involved in the study.

Data Availability Statement: Data supporting reported results are stored in accordance with the ethics requirement of Federation University

Acknowledgments: The author wishes to thank John Fisher for his immense support and supervision of the project and during production of the current paper.

Conflicts of Interest: The author declares no conflict of interest. 


\section{Appendix A}

Table A1. Six emotionally intelligent trait profiles. EI trait levels within each profile predicted differences in how teachers are likely to react emotionally, cognitively and behaviourally using the author's proposed EI Process Model of Stigmatisation (EPS-Model).

\section{Ideal Trait Profile Factors}

\begin{tabular}{|c|c|c|c|}
\hline Significantly Higher in & Significantly Lower in & Significantly Higher in & Significantly Lower in \\
\hline $\begin{array}{l}\text { Self-Esteem }(1,5) \\
\text { Optimism }(1,2,3,5) \\
\text { Empathy }(1,2,3,4,6) \\
\text { Emotion Perception }(1,2,3,4) \\
\text { Assertiveness }(1,5) \\
\text { Emotion Management (in Others) } \\
(1,5,6) \\
\text { Stress Management }(1-6) \\
\text { Self-Motivation }(1,2,3,4) \\
\text { Adaptability }(1,2,3,4,5) \\
\text { Emotion Expression of Self }(2,3) \\
\text { Emotion Expression of Others }(4) \\
\text { Global EI }(1-6)\end{array}$ & $\begin{array}{l}\text { Pessimism } \\
(1,2,3,6)\end{array}$ & $\begin{array}{l}\text { Compassion (1-6) } \\
\text { Self-Efficacy (1-6) } \\
\text { Likely Helping Behaviour } \\
(1-6)\end{array}$ & $\begin{array}{l}\text { Negative Affect }(1,4,5,6) \\
\text { Perception of Student } \\
\text { Responsibility /Fault }(1-6) \\
\text { Perceived Risk (1-6) } \\
\text { Punitive Behaviour (1-6) }\end{array}$ \\
\hline Legend & \multicolumn{3}{|c|}{ Direct Pathways (EI $\rightarrow$ Affect $\rightarrow$ Behaviour) } \\
\hline$(1)$ & Ideal Trait Profile 1 & $\mathrm{EI} \rightarrow$ Negative Affec & ikely Punitive Behaviour \\
\hline \multirow[t]{2}{*}{$(2)$} & Ideal Trait Profile 2 & EI $\rightarrow$ Compassion $\rightarrow$ Like & lping and Punitive Behaviours \\
\hline & \multicolumn{3}{|c|}{ Indirect Pathways (EI $\rightarrow$ Affect $\rightarrow$ Cognitive $\rightarrow$ Behaviour) } \\
\hline (3) & Ideal Trait Profile 3 & $\begin{array}{r}\mathrm{EI} \rightarrow \text { Compassion } \rightarrow \text { Perc } \\
\text { Likely } \mathrm{P}\end{array}$ & $\begin{array}{l}\text { n of Student Responsibility } \rightarrow \\
\text { re Behaviour }\end{array}$ \\
\hline$(4)$ & Ideal Trait Profile 4 & $\mathrm{EI} \rightarrow$ Negative Affect & $\begin{array}{l}\text { Efficacy } \rightarrow \text { Likely Helping } \\
\text { iour }\end{array}$ \\
\hline (5) & Ideal Trait Profile 5 & EI $\rightarrow$ Negative Affect $\rightarrow$ & $\begin{array}{l}\text { eived Risk } \rightarrow \text { Likely Punitive } \\
\text { iour }\end{array}$ \\
\hline (6) & Ideal Trait Profile 6 & $\begin{array}{r}\text { EI } \rightarrow \text { Negative Affect } \rightarrow P \\
\rightarrow \text { Likely }\end{array}$ & $\begin{array}{l}\text { tion of Student Responsibility } \\
\text { ive Behaviour }\end{array}$ \\
\hline
\end{tabular}

\section{References}

1. Andreou, E.; Rapti, A. Teachers' causal attributions for behaviour problems and perceived efficacy for class management in relation to selected interventions. Behav. Chang. 2010, 27, 53-67. [CrossRef]

2. Kokkinos, C.; Panayiotou, G.; Davazoglou, A. Correlates of teacher appraisals of student behaviors. Psychol. Sch. 2005, 42, 79-89. [CrossRef]

3. Poulou, M.; Norwich, B. Cognitive, emotional and behavioural responses to students with emotional and behavioural difficulties: A model of decision-making. Br. Educ. Res. J. 2002, 28, 111-138. [CrossRef]

4. Robertson, R.E.; Kokina, A.A.; Moore, D.W. Barriers to implementing behavior intervention plans: Results of a statewide survey. J. Posit. Behav. Interv. 2020, 22, 145-155. [CrossRef]

5. Sutherland, K.S.; Lewis-Palmer, T.; Stichter, J.; Morgan, P.L. Examining the influence of teacher behavior and classroom context on the behavioral and academic outcomes for students with emotional or behavioral disorders. J. Spec. Educ. 2008, 41, 223-233. [CrossRef]

6. Yeager, D.S.; Dahl, R.E.; Dweck, C.S. Why interventions to influence adolescent behavior often fail but could succeed. Perspect. Psychol. Sci. 2018, 13, 101-122. [CrossRef] [PubMed]

7. Perry, C.; Ball, I. Dealing constructively with negatively evaluated emotional situations: The key to understanding the different reactions of teachers with high and low levels of emotional intelligence. Soc. Psychol. Educ. 2007, 10, 443-454. [CrossRef]

8. Sutherland, K.S.; Oswald, D. The relationship between teacher and student behavior in classrooms for students with emotional and behavioral disorders: Transactional processes. J. Child Fam. Stud. 2005, 14, 1-14. [CrossRef]

9. Jennings, P.; Greenberg, M. The prosocial classroom: Teacher social and emotional competence in relation to student and classroom outcomes. Rev. Educ. Res. 2009, 79, 491-525. [CrossRef]

10. Nizielski, S.; Hallum, S.; Lopes, P.; Schutz, A. Attention to student needs mediates the relationship between teacher emotional intelligence and student misconduct in the classroom. J. Psychoeduc. Assess. 2012, 30, 320-329. [CrossRef] 
11. Westwood, P.; Graham, L. Inclusion of students with special needs: Benefits and obstacles perceived by teachers in New South Wales and South Australia. Aust. J. Learn. Disabil. 2003, 8, 3-15. [CrossRef]

12. Cumming, T. The education of students with emotional and behavioural disabilities in Australia: Current trends and future directions. Interv. Sch. Clin. 2011, 48, 55-59. [CrossRef]

13. Smith, D. Introduction to Special Education: Making A Difference, 6th ed.; Pearson Education, Inc.: London, UK; Claremont Graduate University: Claremont, CA, USA, 2007.

14. American Psychiatric Association. Diagnostic and Statistical Manual of Mental Disorders (DSM-V), 5th ed.; American Psychiatric Association: Washington, DC, USA, 2013.

15. Caldarella, P.; Christensen, L.; Kramer, T.J.; Kronmiller, K. Promoting social and emotional learning in second grade students: A study of the Strong Start curriculum. Early Child Educ. J. 2009, 37, 51-56. [CrossRef]

16. Oliver, R.; Reschly, D. Special education teacher preparation in classroom management: Implication for students with emotional and behavioral disorders. Behav. Disord. 2010, 35, 188-199. [CrossRef]

17. Conway, R. Students with emotional and behavioural disorders: An Australian perspective. Prev. Sch. Fail. 2006, 50, 15-20. [CrossRef]

18. Sullivan, A.M.; Johnson, B.; Owens, L.; Conway, R. Punish them or engage them? teachers' views of unproductive student behaviours in the classroom. Aust. J. Teach. Educ. 2014, 39. [CrossRef]

19. Lannie, A.; McCurdy, B. Preventing disruptive behavior in the urban classroom: Effects of the good behavior game on student and teacher behavior. Educ. Treat. Children 2007, 30, 85-98. [CrossRef]

20. Solar, E. Prove them wrong be there for secondary students with an emotional or behavioral disability. Teach. Except. Child. 2011, 44, 40-45. [CrossRef]

21. Dishion, T.; Dodge, K. Peer contagion in interventions for children and adolescents: Moving towards an understanding of the ecology and dynamics of change. J. Abnorm. Child Psychol. 2005, 33, 395-400. [CrossRef]

22. Dishion, T.J.; Dodge, K.A.; Lansford, J.E. Findings and recommendations: A Blueprint to minimize deviant peer influence in youth interventions and programs. In Deviant Peer Influences in Programs for Youth: Problems And Solutions; Dodge, K.A., Dishion, T.J., Lansford, J.E., Eds.; Guilford: New York, NY, USA, 2006; pp. 366-394.

23. Jones, E.; Margolius, M.; Rollock, M.; Tang Yan, C.; Cole, M.L.; Zaff, J.F. Disciplined and Disconnected: How Students Experience Exclusionary Discipline in Minnesota and the Promise of Non-Exclusionary Alternatives; America's Promise Alliance: Washington, DC, 2018; Available online: https:/ / search.ebscohost.com/login.aspx?direct=true\&AuthType=sso\&db=eric\&AN=ED586336\&site= eds-live\&scope $=$ site (accessed on 1 October 2020).

24. Becker, E.S.; Goetz, T.; Morger, V.; Ranellucci, J. The importance of teachers' emotions and instructional behavior for their students' emotions: An experience sampling analysis. Teach. Teach. Educ. 2014, 43, 15-26. [CrossRef]

25. Chen, J. Exploring the impact of teacher emotions on their approaches to teaching: A structural equation modelling approach. Br. J. Educ. Psychol. 2019, 89, 57-74. [CrossRef] [PubMed]

26. Wang, H.; Hall, N.C. A systematic review of teachers' causal attributions: Prevalence, correlates, and consequences. Front. Psychol. 2018, 17, 2305. [CrossRef] [PubMed]

27. Graham, S. On communicating low ability in the classroom: Bad things good teachers sometimes do. In Attribution theory: Applications to Achievement, Mental Health, and Interpersonal Conflict; Graham, S., Folkes, V., Eds.; Erlbaum: Hillsdale, NJ, USA, 1990; pp. 17-36.

28. Kokkinos, C. Job stressors, personality and burnout in primary school teachers. Br. J. Educ. Psychol. 2007, 77, 229-243. [CrossRef] [PubMed]

29. Cooper, P. Teacher strategies for effective intervention with students presenting social, emotional and behavioural difficulties: An international review. Eur. J. Spec. Needs Educ. 2011, 26, 71-86. [CrossRef]

30. Nurmi, J. Students' characteristics and teacher-child relationships in instruction: A meta-analysis. Educ. Res. Rev. 2012, 7, 177-197. [CrossRef]

31. Cunningham, B.; Sugawara, A. Factors contributing to preservice teachers' management of children's problem behaviors. Psychol. Sch. 1989, 26, 370-379. [CrossRef]

32. Link, B.; Phelan, J. Conceptualizing stigma. Annu. Rev. Sociol. 2001, 27, 363-385. [CrossRef]

33. Lam, C.; Tsang, H.; Chan, F.; Corrigan, P. Chinese and American perspectives on stigma. Rehab. Educ. 2006, 20, 269-279. [CrossRef]

34. Hughes, J.; Barker, D.; Kemenoff, S.; Hart, M. Problem ownership, causal attributions and self-efficacy as predictors of teachers' referral decisions. J. Educ. Psychol. Consult. 1993, 4, 369-384. [CrossRef]

35. Soodak, L.C.; Podell, D.M. Teachers' thinking about difficult-to-teach students. J. Educ. Res. 1994, 88, 44-51. [CrossRef]

36. Corrigan, P.; Markowitz, F.; Watson, A.; Rowan, D.; Kubiak, M. An attribution model of public discrimination towards persons with mental illness. J. Health Soc. Behav. 2003, 44, 162-179. [CrossRef] [PubMed]

37. Weiner, B. An attributional theory of achievement motivation and emotion. Psychol. Rev. 1985, 92, 548-573. [CrossRef] [PubMed]

38. Weiner, B.; Perry, R.P.; Magnusson, J. An attributional analysis of reactions to stigmas. J. Pers. Soc. Psychol. 1988, 55, 738-748. [CrossRef] [PubMed]

39. Weiner, B. Inferences of responsibility and social motivation. In Advances in Experimental Social Psychology; Zanna, M.P., Ed.; Academic Press: San Diego, CA, USA, 1995; pp. 1-47.

40. Weiner, B. A theory of motivation for some classroom experiences. J. Educ. Psychol. 1979, 71, 3-25. [CrossRef] 
41. Weiner, B. A cognitive (attribution)-emotion-action model of motivated behavior: An analysis of judgments of help-giving. J. Pers. Soc. Psychol. 1980, 39, 186. [CrossRef]

42. Weiner, B. Some methodological pitfalls in attributional research. J. Educ. Psychol. 1983, 75, 530-543. [CrossRef]

43. Corrigan, P.W. Mental health stigma as social attribution: Implications for research methods and attitude change. Clin. Psychol. (New York) 2000, 7, 48-67. [CrossRef]

44. Coleman, D.; Walker, J.S.; Lee, J.; Friesen, B.J.; Squire, P.N. Children's beliefs about causes of childhood depression and ADHD: A study of stigmatization. Psychiatr. Serv. 2009, 60, 950-957. [CrossRef]

45. Martin, J.; Pescosolido, B.; Tuch, S. Of fear and loathing: The role of 'disturbing behavior', labels, and causal attributions in shaping public attitudes toward people with mental illness. J. Health Soc. Behav. 2000, 41, 208-223. [CrossRef]

46. Menec, V.; Perry, R. Reactions to stigmas among Canadian students: Testing an attribution-affect-help judgment model. J. Soc. Psych. 1998, 138, 443-453. [CrossRef]

47. Rush, L.L. Affective reactions to multiple social stigmas. J. Soc. Psychol. 1998, 138, 421-430. [CrossRef]

48. Steins, G.; Weiner, B. The influence of perceived responsibility and personality characteristics on the emotional and behavioral reactions to people with AIDS. J. Soc. Psychol. 1999, 139, 487-495. [CrossRef] [PubMed]

49. Weiner, B.; Graham, S.; Chandler, C. Pity, anger, and guilt: An attributional analysis. Pers. Soc. Psychol. Bull. 1982, 8, $226-232$. [CrossRef]

50. Weiner, B. May I borrow your class notes? An attributional analysis of judgments of help-giving in an achievement-related context. J. Educ. Psychol. 1980, 72, 676-681. [CrossRef]

51. Taylor, L.; Hume, R.; Welsh, N. Labelling and self-esteem: The impact of using specific vs. generic labels. Educ. Psychol. Int. J. Exp. Educ. Psychol. 2010, 30, 191-202. [CrossRef]

52. Nemer, S.L.; Sutherland, K.S.; Chow, J.C.; Kunemund, R.L. A systematic literature review identifying dimensions of teacher attributions for challenging student behavior. Educ. Treat. Children 2019, 42, 557-578. [CrossRef]

53. Adina, C.; Clipa, O. Teachers' satisfaction with life, job satisfaction and their emotional intelligence. Procedia Soc. Behav. Sci. 2012, 33, 498-502. [CrossRef]

54. Penrose, A.; Perry, C.; Ball, I. Emotional intelligence and teacher self efficacy: The contribution of teacher status and length of experience. Issues Educ. Res. 2007, 17, 107-126.

55. Rastegar, M.; Memarpour, S. The relationship between emotional intelligence and self-efficacy among Iranian EFL teachers. System 2009, 37, 700-707. [CrossRef]

56. Şenel, E.; Adiloğulları, İ.; Ulucan, H. Examination of emotional intelligence level, teacher's self-efficacy beliefs and general self-efficacy beliefs of teachers. Niğde Univ. J. Phys. Educ. Sport Sci. 2014, 8, 225-232.

57. Wertheim, C.; Leyser, Y. Efficacy beliefs, background variables, and differentiated instruction of Israeli prospective teachers. J. Educ. Res. 2002, 96, 54-63. [CrossRef]

58. Rich, Y.; Lev, S.; Fisher, S. Extending the concept and assessment of teacher efficacy. Educ. Psychol. Meas. 1996, 56, 1015-1025. [CrossRef]

59. Emmer, E.T.; Stough, L.M. Classroom management: A critical part of educational psychology, with implications for teacher education. Educ. Psychol. 2001, 36, 103-112. [CrossRef]

60. Almog, O.; Shechtman, Z. Teachers' democratic and efficacy beliefs and styles of coping with behavioural problems of pupils with special needs. Eur. J. Spec. Needs Educ. 2007, 22, 115-129. [CrossRef]

61. Ross, J.A.; Bruce, C. Self-assessment and professional growth: The case of a grade 8 mathematics teacher. Teach. Teach. Educ. 2007, 23, 146-159. [CrossRef]

62. Bailey, B.A.; Hare, D.J.; Hatton, C.; Limb, K. The response to challenging behaviour by care staff: Emotional responses, attributions of cause and observations of practice. J. Intellect. Disabil. Res. 2006, 50, 199-211. [CrossRef]

63. Corrigan, P.W. Testing social cognitive models of mental illness stigma: The Prairie State stigma studies. Psychiatr. Rehabil. Skills 2002, 6, 232-254. [CrossRef]

64. Angermeyer, M.C.; Matschinger, H. The effect of violent attacks by schizophrenic persons on the attitude of the public towards the mentally ill. Soc. Sci. Med. 1996, 43, 1721-1728. [CrossRef]

65. Levey, S.; Howells, K. Dangerousness, unpredictability and the fear of people with schizophrenia. J. Forens. Psychiatr. 1995, 6, 19-39. [CrossRef]

66. Link, B.G.; Cullen, F.T. Contact with the mentally ill and perceptions of how dangerous they are. J. Health Soc. Behav. 1986, 27, 289-302. [CrossRef]

67. Wolff, G.; Pathare, S.; Craig, T.; Leff, J. Community knowledge of mental illness and reaction to mentally ill people. Br. J. Psychiatr. 1996, 168, 191-198. [CrossRef] [PubMed]

68. Lazarus, R.S. Thoughts on the relations between emotion and cognition. Am. Psychol. 1982, 37, 1019-1024. [CrossRef]

69. Mayer, J.D.; Gaschke, Y.N.; Braverman, D.L.; Evans, T.W. Mood congruent judgment is a general effect. J. Pers. Soc. Psychol. 1992, 63, 119-132. [CrossRef]

70. Parrott, W.G. The nature of emotion. In Blackwell Handbook of Social Psychology: Intraindividual Processes; Tesser, A., Schwarz, N., Eds.; Blackwell Publishers IncNiz: Malden, MA, USA, 2001; pp. 375-390.

71. Cole, T. Understanding: A prerequisite to inclusion. In Promoting Inclusive Practice; Tilstone, C., Florian, L., Rose, R., Eds.; Routledge: London, UK, 1998; pp. 113-126. 
72. Sugai, G.; Evans, D. Using teacher perceptions to screen for primary students with high risk behaviours. Australas. J. Spec. Educ. 1997, 21, 18-35. [CrossRef]

73. Ashford, S.J.; Tsui, A.S. Self-regulation for managerial effectiveness: The role of active feedback seeking. Acad. Manag. J. 1991, 34, 251-280. [CrossRef]

74. Beeftink, F.; Van Eerde, W.; Rutte, C.G.; Bertrand, J.W. Being successful in a creative profession: The role of innovative cognitive style, self-regulation, and self-efficacy. J. Bus. Psychol. 2012, 27, 71-81. [CrossRef]

75. Lord, R.G.; Diefendorff, J.M.; Schmidt, A.M.; Hall, R.J. Self-regulation at work. Annu. Rev. Psychol. 2010, 61, 543-568. [CrossRef]

76. Sutton, R.E. Emotional regulation goals and strategies of teachers. Soc. Psychol. Educ. 2004, 7, 379-398. [CrossRef]

77. Coplan, R.J.; Hughes, K.; Bosacki, S.; Rose-Krasnor, L. Is silence golden? Elementary school teachers' strategies and beliefs regarding hypothetical shy/quiet and exuberant/talkative children. J. Educ. Psychol. 2011, 103, 939. [CrossRef]

78. Lopes, P.; Nezlek, J.; Extremera, N.; Hertel, J.; Fernández-Berrocal, P.; Schütz, A.; Salovey, P. Emotion regulation and the quality of social interaction: Does the ability to evaluate emotional situations and identify effective responses matter? J. Pers. 2011, 79, 429-467. [CrossRef]

79. Petrides, K.V.; Pita, R.; Kokkinaki, F. The location of trait emotional intelligence in personality factor space. Br. J. Psychol. 2007, 98, 273-289. [CrossRef] [PubMed]

80. Cherniss, C. Emotional Intelligence: Towards clarification of a concept. Ind. Organ. Psychol. 2010, 3, 110-126. [CrossRef]

81. Passmore, J. Excellence in Coaching: The Industry Guide, 2nd ed.; Kogan Page Publishers: London, UK, 2010.

82. Mayer, J.D.; Salovey, P.; Caruso, D.R. Emotional intelligence: New ability or eclectic traits? Am. Psychol. 2008, 63, 503-517. [CrossRef]

83. Bar-On, R. The Emotional Intelligence Inventory (EQ-i): Technical Manual; Multi-Health Systems: Toronto, ON, Canada, 1997.

84. Bar-On, R. BarOn Emotional Quotient Inventory: Facilitator's Resource Manual; Multi-Health Systems: Toronto, ON, Canada, 1997.

85. Bar-On, R. The Bar-On model of emotional-social intelligence. Psicothema 2006, 18, 13-25.

86. Goleman, D. Emotional intelligence: Perspectives on a theory of performance. In The Emotionally Intelligent Workplace; Cherniss, C., Goleman, D., Eds.; Jossey-Bass Publication: San Francisco, CA, USA, 2001.

87. Petrides, K.V. Trait emotional intelligence theory. Ind. Organ. Psychol. 2010, 3, 136-139. [CrossRef]

88. Petrides, K.V. A Psychometric Investigation into the Construct of Emotional Intelligence. Ph.D. Thesis, University College, London, UK, 2001.

89. Weiner, B. An Attributional Theory of Motivation and Emotion; Springer-Verlag: New York, NY, USA, 1986.

90. Dooley, P.A. Perceptions of the onset-controllability of AIDS and helping judgments: An attributional analysis. J. Appl. Soc. Psychol. 1995, 25, 858-869. [CrossRef]

91. Reisenzein, R. A structural equation analysis of Weiner's attribution: Affect model of helping behaviour. J. Pers. Soc. Psychol. 1986, 50, 1123-1133. [CrossRef]

92. Willner, P.; Smith, S. Attribution theory applied to helping behaviour towards people with intellectual disabilities who challenge. J. Appl. Res. Intellect. Disabil. 2008, 21, 150-155. [CrossRef]

93. Petrides, K.V. Technical Manual for the Trait Emotional Intelligence Questionnaires (TEIQue); London Psychometric Laboratory: London, UK, 2009.

94. Austin, E.; Parker, J.; Petrides, K.; Saklofske, D.H. Emotional intelligence. In The SAGE Handbook of Personality Theory and Testing, Vol. 1: Personality Theories and Models; Boyle, G., Matthews, G., Saklofske, D., Eds.; Sage: Thousand Oaks, CA, USA, 2008.

95. Goetz, J.L.; Keltner, D.; Simon-Thomas, E. Compassion: An evolutionary analysis and empirical review. Psychol. Bull. 2010, 136, 351-374. [CrossRef]

96. Thomas, C.; Rose, J. The relationship between reciprocity and the emotional and behavioural responses of staff. J. Appl. Res. Intellect. Disabil. 2010, 23, 167-178. [CrossRef]

97. Schmidt, F.L.; Hunter, J.E. Development of a general solution to the problem of validity generalization. J. Appl. Psychol. 1977, 62, 529-540. [CrossRef]

98. Schmidt, F.L.; Hunter, J.E. The validity and utility of selection methods in personnel psychology: Practical and theoretical implications of 85 years of research findings. Psychol. Bull. 1998, 124, 262-274. [CrossRef]

99. Petrides, K.V. Psychometric properties of the Trait Emotional Intelligence Questionnaire. In Advances in the Assessment of Emotional Intelligence; Stough, C., Saklofske, D.H., Parker, J.D., Eds.; Springer: New York, NY, USA, 2009.

100. Link, B.G.; Yang, L.H.; Phelan, J.C.; Collins, P.Y. Measuring mental illness stigma. Schizophr. Bull. 2004, 30, 512-541. [CrossRef] [PubMed]

101. Ajzen, I. The theory of planned behavior. Organ. Behav. Hum. Decis. Process 1991, 50, 179-211. [CrossRef]

102. Orbell, S.; Hodgkins, S.; Sheeran, P. Implementation intentions and the theory of planned behaviour. Pers. Soc. Psychol. Bull. 1997, 23, 945-954. [CrossRef] 